\title{
Perirhinal Cortex Muscarinic Receptor Blockade Impairs Taste Recognition Memory Formation
}

\author{
Ranier Gutiérrez, Vanesa De la Cruz, Carlos J. Rodriguez-Ortiz, \\ and Federico Bermudez-Rattoni ${ }^{1}$ \\ Instituto de Fisiología Celular, Universidad Nacional Autónoma de México, AP 70-253, 04510 Cd. México, DF, México
}

\begin{abstract}
The relevance of perirhinal cortical cholinergic and glutamatergic neurotransmission for taste recognition memory and learned taste aversion was assessed by microinfusions of muscarinic (scopolamine), NMDA (AP-5), and AMPA (NBQX) receptor antagonists. Infusions of scopolamine, but not AP5 or NBQX, prevented the consolidation of taste recognition memory using attenuation of neophobia as an index. In addition, learned taste aversion in both shortand long-term memory tests was exclusively impaired by scopolamine. These data provide neurochemical support for the theory that cholinergic activity of the perirhinal cortex participates in the formation of the taste memory trace and that it is independent of the NMDA and AMPA receptor activity. These results support the idea that cholinergic neurotransmission in the perirhinal cortex is also essential for acquisition and consolidation of taste recognition memory.
\end{abstract}

Perirhinal cortex has been defined as a higher-order polymodal associational cortex because it receives both unimodal input from all sensory modalities as well as afferents from polymodal association areas (Burwell 2001). The principal pathways come from frontal, parietal, temporal, cingulate, occipital, and subicular cortices (Deacon et al. 1983). In addition, perirhinal cortex sends direct and indirect (through entorhinal cortex) projections to the hippocampus (Burwell and Amaral 1998), a structure involved in plasticity and learning (Martin and Morris 2002). Moreover, it should be noted that the perirhinal cortex is interconnected with the amygdala and the insular cortex (McDonald and Jackson 1987; Burwell and Amaral 1995), brain regions responsible for gustatory learning and memory in the rat (Lamprecht and Dudai 1996; Yasoshima and Yamamoto 1997; BermudezRattoni and Yamamoto 1998).

Lesions to the perirhinal cortex induce several cognitive deficits that range from difficulties recognizing an item that has been previously presented (recognition memory; Mandler 1980), to impairments in cross-modal associative memories (for review, see Murray and Richmond 2001). For example, damage to the perirhinal and entorhinal cortices (referred to as rhinal cortex) impairs cross-modal tactual-visual recognition memory (Goulet and Murray 2001) as well as cross-modal flavor-visual associative memory in which the monkey must use an association between a food cue and a visual object to get a food reward (Parker and Gaffan 1998). In addition, injury to the perirhinal cortex (Meunier et al. 1993; Mumby and Pinel 1994; Malkova et al. 2001) as well as perirhinal microinjections of the cholinergic muscarinic receptor blocker scopolamine impair visual recognition memory (Tang et al. 1997), whereas intraperitoneal administration of physostigmine, a cholinesterase inhibitor, improves it (Aigner and Mishkin 1986). These results indicate the relevance of the perirhinal cortex cholinergic activity for normal visual recognition memory. In addition, diminished performance on tactual (Buffalo et al. 1999) and olfactory recognition memory tasks has been reported in animals lacking perirhinal cortex (Otto and Eichenbaum 1992). However, auditory recognition memory is not affected by lesions of the perirhinal cortex (Kowalska et al. 2001).

'Corresponding author.

E-MAIL fbermude@ifc.unam.mx; FAX (525) 622-5607.

Article and publication are at http://www.learnmem.org/cgi/doi/10.1101/ Im.69704.
Scarce information about the participation of perirhinal cortex on taste recognition memory is available in the literature (Brown and Xiang 1998). Because eating and drinking are multimodal integration processes, that is, the aspect (visual), odor (olfactory), texture (somatosensory), and taste of a foodstuff must be integrated in specific brain regions to predict how tasty or disgusting an edible might be, and because it is known that the perirhinal cortex integrates almost all sensory modalities to identify an object as the same even in different contexts or perspectives (Murray and Richmond 2001), the perirhinal cortex emerges as a plausible integration region of taste information with that of other sensory systems. In this regard, it was reported that perirhinal cortex is involved in conditioned taste aversion (CTA), in which a palatable taste changes from positive to aversive because of a malaise-inducing agent injection. Thus, Tassoni et al. (2000), using a sodium channel blocker (TTX), reported that temporal inactivation of the perirhinal cortex when rats drink a novel taste solution impairs CTA, but the impairment was not observed when inactivation was induced between taste exposure and induction of malaise (association phase) or before the retrieval test. These results indicate that the perirhinal cortex is involved in the formation of the taste memory trace (TMT; for definition, see Gutierrez et al. 2003b), but not in the association or retrieval of learned taste aversion.

Therefore, in this study we assessed the participation of cholinergic and glutamatergic receptors of the perirhinal cortex on taste recognition memory and learned taste aversion. We used the innate neophobic behavior as a novelty index. This behavior consists of a reduced fluid consumption that rats show when exposed to a novel taste solution. This response is attenuated in subsequent presentations (Nachman and Jones 1974; Domjan 1976); that is, rats drink more when the taste is familiar. Attenuation of neophobia (AN) was therefore used as an index of taste recognition memory. It should be stressed that AN is a long lasting behavior that persists for days (Buresova and Bures 1980) or even months (Best et al. 1978), and it is dependent on muscarinic receptor activity of the insular cortex (gustatory cortex; Gutierrez et al. 2003a,b).

To evaluate in more detail the participation of perirhinal cortex on learned taste aversion, microinjections of scopolamine were performed in this area. It has been previously demonstrated that scopolamine impairs specifically the formation of the TMT 
when it is injected in the insular cortex (Naor and Dudai 1996; Ferreira et al. 2002; Gutierrez et al. 2003b). In addition, NMDA and AMPA receptor blockers were also applied because previous reports indicate that glutamatergic activity is required in the insular cortex for CTA long-term memory but not for taste memory trace formation (Ferreira et al. 2002; Gutierrez et al. 2003a,b).

\section{RESULTS}

\section{Taste Recognition Memory}

To assess the role of muscarinic, NMDA, and AMPA receptors in the perirhinal cortex on taste recognition memory, respective antagonists were microinjected either before or after novel taste presentation. A highly concentrated saccharin solution $(0.5 \%)$ was used, which is known to increase the robustness of neophobia; that is, rats innately drink much less saccharin solution in comparison with their normal water consumption (cf. Fig. 1, first sacch vs. Fig. 2, acquisition). All animals showed comparable neophobic response to saccharin $\left(F_{(3,82)}=1.1 ; p>0.05\right)$, drinking on average only $31 \%(3.7 \pm 0.25 \mathrm{~mL})$ relative to water baseline (Fig. 1A,B). On the second taste experience (Fig. 1A, second sacch), the group treated with scopolamine drank similar levels of saccharin solution as in the previous presentation, whereas all the other groups increased their saccharin intake, showing the expected attenuation of neophobia $\left(F_{(3,47)}=14 ; p<0.0001\right)$. In the third taste experience (third sacch), there were still significant differences between the scopolamine group and the vehicle group $\left(F_{(3,47)}=5, p<0.01\right)$. However, despite these differences, rats that received scopolamine displayed a normal attenuation of neophobia because they drank as the control group did during their second saccharin intake. These results indicate that scopolamine does not induce a permanent effect on taste recognition. It should be noted that the activity of scopolamine lasts less than $24 \mathrm{~h}$ (Sipos et al. 1999), and it was only injected on the first saccharin presentation.

The results were similar when scopolamine was microinjected immediately after novel taste presentation; that is, there were no significant differences on the first saccharin intake $\left(F_{(1,35)}=2.8, p>0.05\right)$. However, on the second taste experience, scopolamine prevented attenuation of neophobia $\left(F_{(1,35)}=83.5\right.$, $p<0.0001)$. Moreover, on the third taste presentation, there were still significant differences among groups $\left(F_{(1,35)}=7.8, p>0.01\right.$; Fig. 1B).

As can be seen in Figure 1A, the inactivation of AMPA or NMDA receptors before taste presentation did not impair neophobia or attenuation of neophobia, which indicates that taste recognition memory can persist even in the absence of activity of these receptors in the perirhinal cortex.

\section{Long-Term Memory of Learned Taste Aversion}

Microinjection of scopolamine, AP-5 or NBQX in the perirhinal cortex, was performed to assess their effect on conditioned taste aversion using a 15-min long-term memory test $72 \mathrm{~h}$ after the acquisition trial (as described below in "Behavioral Procedures and Experimental Design"). In all the experiments described herein, neither weight nor baseline water intake was significantly different among the groups (data not shown).

The four groups that received either vehicle, scopolamine or AP-5 or NBQX microinjection, 20 min before the acquisition trial (see Materials and Methods) showed similar consumption of a novel $0.1 \%$ saccharin during a $15-\mathrm{min}$ session compared with water baseline intakes $\left(F_{(3,36)}=1.8, p>0.05\right)$. The means $( \pm$ SEM) were $14.4 \pm 1.2 \mathrm{~mL}, 12.1 \pm 0.85 \mathrm{~mL}, 13.6 \pm 0.90 \mathrm{~mL}$, and $14.3 \pm 1.1 \mathrm{~mL}$ for each of the Veh, Scop, AP5, and NBQX groups, respectively. However, as can be seen in Figure $2 \mathrm{~A}$, on the second taste presentation (LTM test) the control group as well as the AP5and NBQX-treated groups showed similar reductions on saccharin intake, indicating comparable levels of learned taste aversion, unlike the Scop group, which drank substantially more saccharin solution than the other groups $\left(F_{(3,36)}=4.7, p<0.01\right)$.

Because scopolamine impaired CTA when injected before taste presentation, we decided to analyze its effects on tastemalaise association phase. Therefore, this drug was microinjected immediately after taste but before malaise induction. As can be seen in Figure 2B, the differences between vehicle and scopolamine groups were not statistically different on the acquisition day $\left(F_{(1,13)}=0.80, p>0.05\right)$. On the test trial, the means $( \pm$ SEM $)$ were $13.8 \pm 0.80 \mathrm{~mL}$ for the Veh-A and $13.3 \pm 1.2 \mathrm{~mL}$ for the Scop-A group; there were no significant differences between groups $\left(F_{(1,13)}=0.05, p>0.05\right)$. These results indicate that scopolamine's impairment observed on CTA is limited to an early taste processing phase.
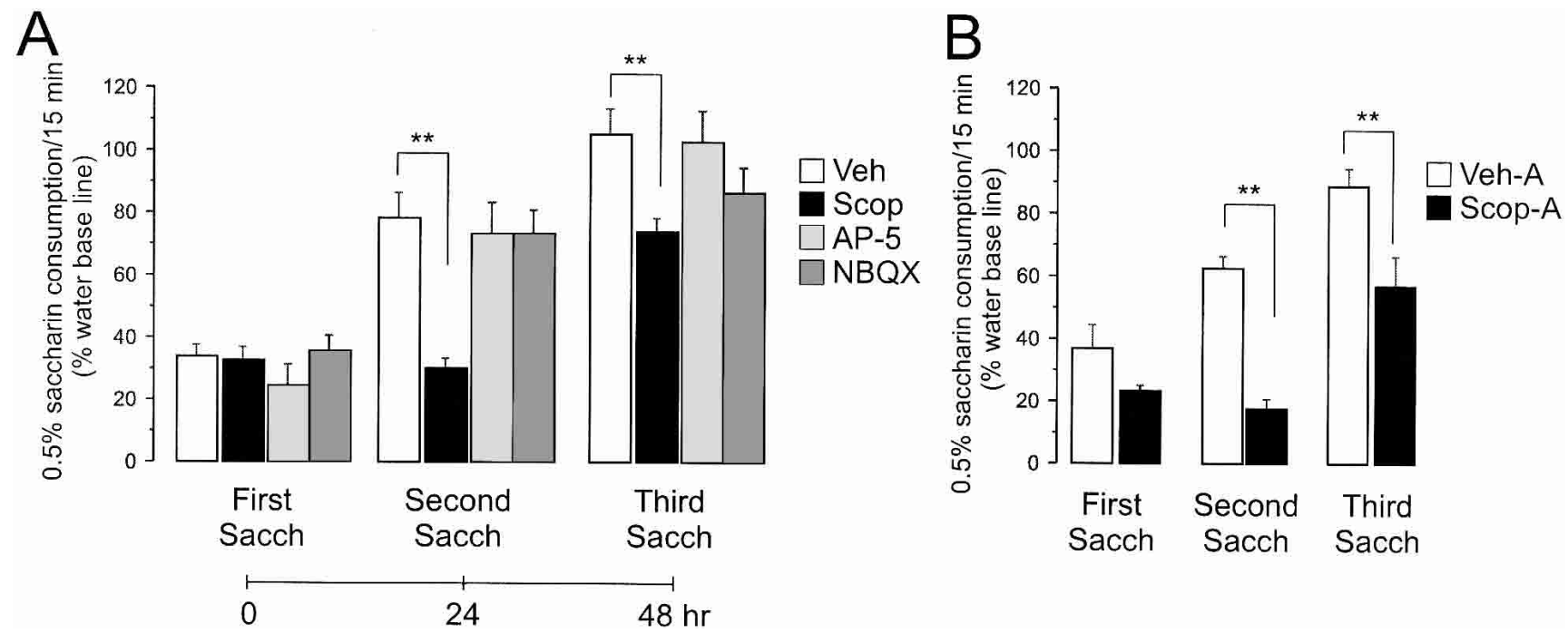

Figure 1 Percentage of consumption (mean \pm SEM) during the first (novel), second (familiar), and third $0.5 \%$ sodium saccharin (sacch) presentation compared with water baseline; every saccharin presentation was given at 24-h intervals. Drugs were injected before $(A)$ or immediately after $(B)$ taste presentation. 

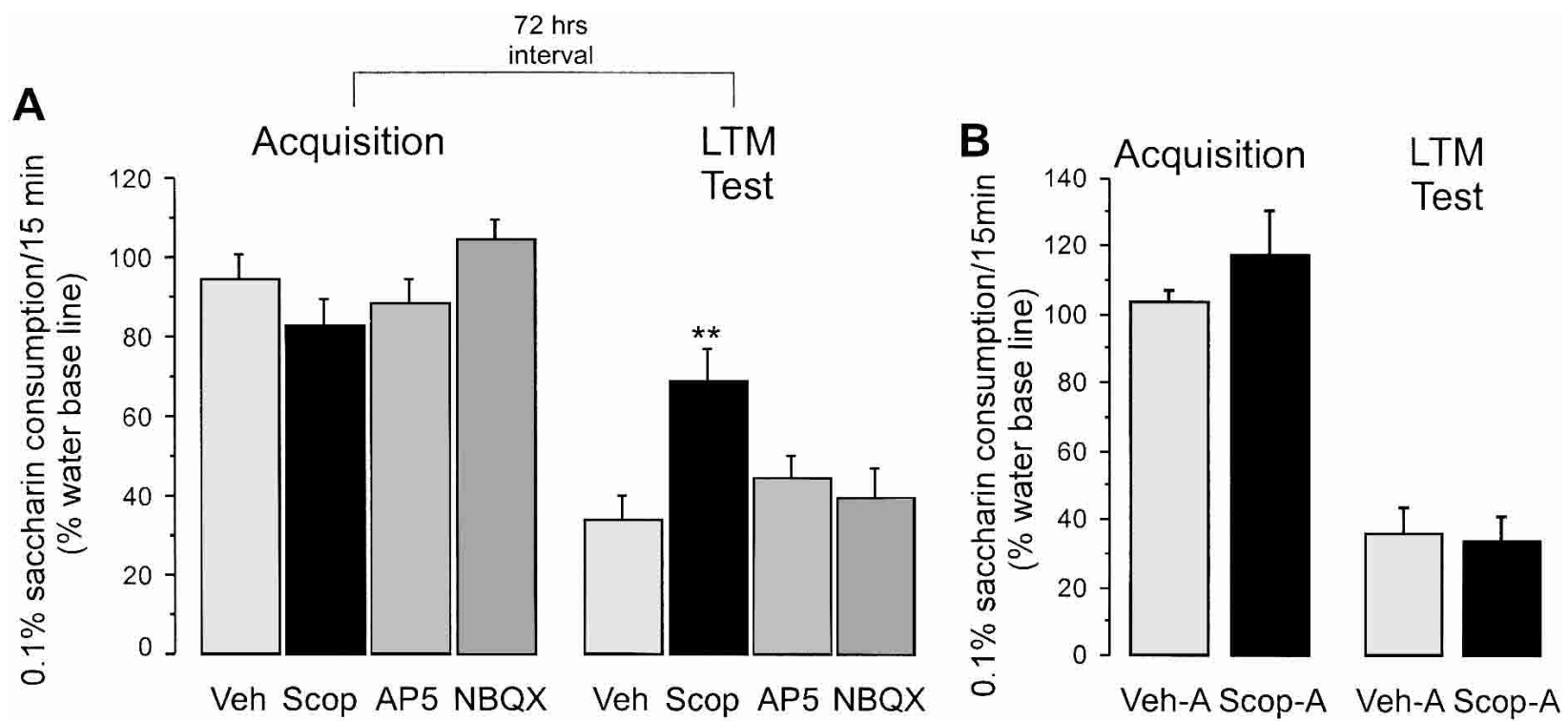

Figure 2 Effect of muscarinic receptor antagonist, scopolamine (Scop), NMDA receptor antagonist, (AP-5), AMPA receptor antagonist (NBQX), and vehicle (Veh) microinjected bilaterally into the perirhinal cortex upon conditioned taste aversion (CTA). (A) The microinjection was given 20 min before taste presentation on the acquisition day (saccharin followed by malaise-inducing agent injection; LiCl). (B) The microinjection was given immediately after taste exposure but before malaise induction on the acquisition day. In both $A$ and $B$ the long-term memory test (LTM; saccharin) was given $72 \mathrm{~h}$ after the acquisition trial. $\left.{ }^{* *}\right) p<0.01$ significantly different among groups.

\section{Short-Term Memory of Learned Taste Aversion}

The observed effects by scopolamine on long-term memory could be due to disruption of the TMT. Because it has been reported that muscarinic receptor blockade of the insular cortex impairs both short- and long-term memory of CTA (Ferreira et al. 2002), we decided to analyze its participation on the latter kind of memory. Therefore, scopolamine was microinjected in the perirhinal cortex 20 min before novel taste presentation, and these animals received a 15-min short-term memory test $4.5 \mathrm{~h}$ after acquisition trial (as described in Materials and Methods), as well as the long-term memory test.

On the acquisition trial, both vehicle and scopolamine groups drank the complete $10-\mathrm{mL}$ saccharin solution ration used. As can be seen in Figure 3, during the short-term memory test there were differences between groups $\left(F_{(1,17)}=8.1, p<0.05\right)$. The scopolamine-treated group drank more saccharin solution than the control group, drinking $6.9 \pm 1.2 \mathrm{~mL}(56 \%)$ of saccharin solution compared with $2.7 \pm 0.73 \mathrm{~mL}(21 \%)$ for the control group (Fig. 3). These results indicate that, unlike vehicle, scopolamine treatment impairs short-term memory of CTA. Remarkably, neither water intake $\left(F_{(1,17)}=3.9, p>0.05\right.$; Veh, $6.6 \pm 0.46$; Scop, $4.4 \pm 1.2$ ) nor total fluid consumption (saccharin plus water) $\left(F_{(1,17)}=1.8, p>0.05\right.$; Veh, $9.3 \pm 0.70$; Scop, $\left.11.3 \pm 1.2\right)$ was significantly different between the groups.

The scopolamine group also drank more saccharin solution than the vehicle group in the long-term memory test $\left(F_{(1,17)}=23.9, p<0.0001\right)$. These results confirm the participation of perirhinal cortical muscarinic receptors on long-term memory of CTA (Fig. 2). Nevertheless, it was observed that the scopolamine-treated group drank more saccharin in the longterm memory test in this experiment, when a STM test was given, than they drank in previous experiments when the STM test was not performed (cf. the Scop group in Fig. 2A vs. Fig. 3). A comparison was made between the effect of scopolamine in both experiments. A two-way ANOVA (treatment [Veh vs. Scop] $\times$ experiment [with STM vs. without STM test]) revealed significant effect of treatment $\left(F_{(1,34)}=31.4 ; p<0.0001\right)$ and experiment $\left(F_{(1,34)}=18.7, p<0.0001\right)$, but not for treat- ment $\times$ experiment interaction $\left(F_{(1,34)}=3, p>0.05\right)$, meaning that in both experiments scopolamine impaired the long-term memory test. However, saccharin intake was different between experiments as indicated by the ANOVA analysis. A subsequent one-way ANOVA for these groups $\left(F_{(3,34)}=18.6, p<0.0001\right)$ and a post hoc test demonstrated that both scopolamine-treated groups are different $(p<0.0001)$ but vehicle groups are not $(p>0.05)$. This distinction might be caused by an accelerated extinction process triggered during the STM test on the scopolamine-infused group, reflecting the impairment induced by this treatment.

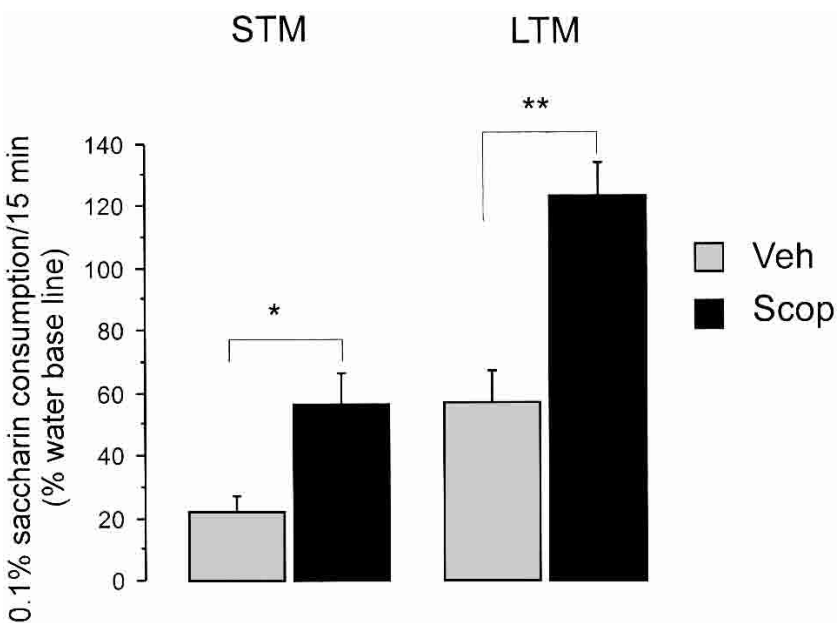

Figure 3 Effect of scopolamine (Scop) or vehicle (Veh) microinjected into perirhinal cortex 20 min before taste presentation on the acquisition day upon short-term memory (STM) and long-term memory (LTM) of conditioned taste aversion (CTA). To measure STM, both groups were presented with saccharin solution for the second time, $4.5 \mathrm{~h}$ after the acquisition trial. Three days after that, the LTM test was performed; that is, rats drank $0.1 \%$ saccharin solution for the third time during $15 \mathrm{~min} .\left(^{*}\right)$ $p<0.05$; $\left({ }^{*}\right) p<0.0001$ for difference between groups with respect to the control group. 


\section{Histology}

According to Burwell (2001), perirhinal cortex comprises two narrow strips of cortex, areas 35 and 36, that are located along the rhinal sulcus. Figure 4 shows two representative sites of microinjection. In the first subject (Fig. 4A), the injector tip was localized just above area 36, whereas for the second subject (Fig. 4B), it was in area 35 (ectorhinal and perirhinal cortex, respectively, according to Paxinos and Watson 1998).

Although the rostral limit of perirhinal cortex is still controversial, we adopted the criteria used by Burwell (2001). Thus, we took the rostral perirhinal cortex as arising at the caudal limit of the claustrum, which equals $-2.56 \mathrm{~mm}$ from Bregma (Paxinos and Watson 1998), whereas the caudal limit was considered as $-6.72 \mathrm{~mm}$ from Bregma. Figure 4 shows the most rostral and caudal injection sites. All the microinjections were given in the anterior portion of the perirhinal cortex approximately from -3 $\mathrm{mm}$ to $-3.6 \mathrm{~mm}$ relative to Bregma. One animal was excluded because of misplaced cannulae.

\section{DISCUSSION}

In the present report we studied the participation of perirhinal muscarinic, NMDA, and AMPA receptors in two different gustatory learned behaviors: conditioned taste aversion and attenuation of neophobia. Our results indicate that blockade of cholinergic muscarinic receptors but not NMDA or AMPA receptors in the perirhinal cortex impaired taste recognition memory as well as conditioned taste aversion. It is well known that the amygdala is important for learned taste aversion, neophobia, and attenuation of neophobia (Ellis and Kesner 1981; Yasoshima et al. 2000). Because the amygdala is anatomically close to perirhinal cortex (see Fig. 4), it might be possible that the effects observed are attributable to leakage of the drugs into this structure instead of blockade of the perirhinal cortex. However, several facts support the argument against this possibility. First, a small volume of 0.5 $\mu \mathrm{L}$ was injected per hemisphere (Myers 1966). Second, it has been reported that infusion of AP-5 or NBQX in the basolateral amygdala impairs CTA learning to saccharin (Yasoshima et al. 2000), whereas we did not find any significant effect on CTA with the same drugs. Fitzgerald and Burton (1983) reported that electro-
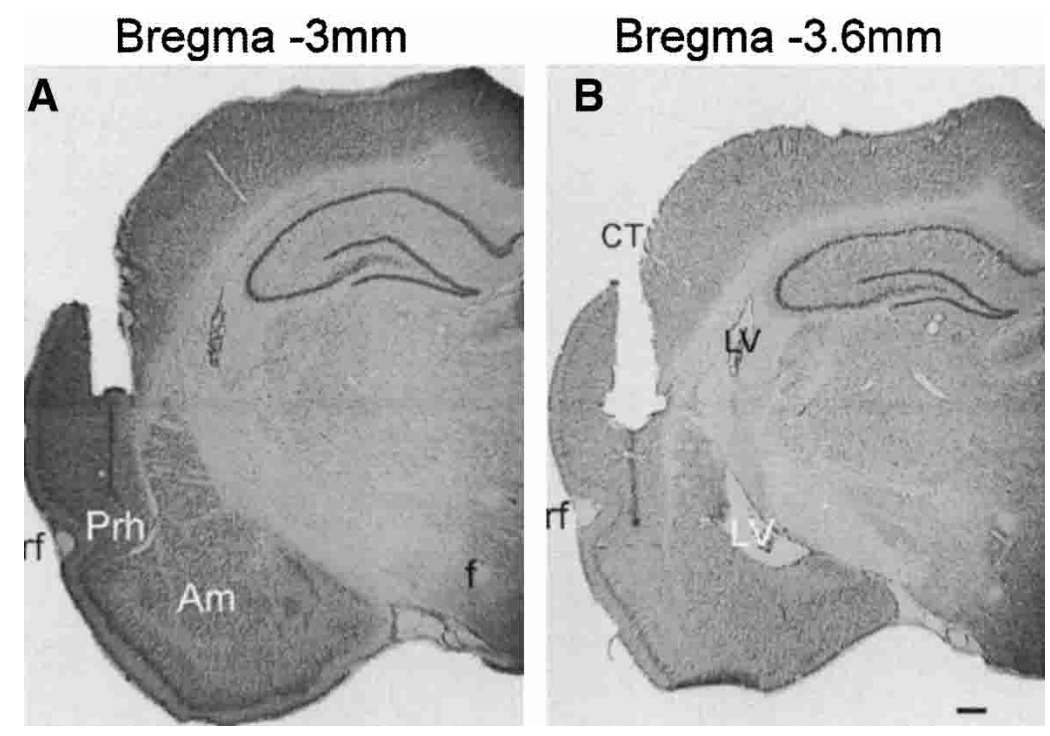

Figure 4 Photomicrograph of coronal rat brain sections, stained with Cresyl Violet, showing the cannula tract (CT) and the scar left by the injector and injection tip in the perirhinal cortex on two different rats $(A, B)$. See text for explanation. (rf) Rhinal sulcus; (Prh) perirhinal cortex; (Amy) amygdala; (LV) lateral ventricle; and (f) fornix. Bar scale, $0.5 \mathrm{~mm}$. lytic amygdala lesions or severing the connection between the amygdala and the temporal cortex (perirhinal connections included) produce similar deficits on neophobia. However, in the present report neither cholinergic nor glutamatergic receptor antagonists disrupted neophobia, which not only shows that the effects observed were caused by blockade of perirhinal cholinergic activity but also ruled out the idea that the effects of scopolamine were due to impaired taste perception.

As proposed previously (Domjan 1976), novelty seems to enhance the aversive qualities of a highly concentrated saccharin solution (Bartoshuk 1979; Smith 2000). However, animals overcome this neophobia, displaying higher saccharin consumption on subsequent presentations, which reflects a learning process (Gutierrez et al. 2003b). Therefore, we used the neophobic response as a novelty detection index and the subsequent attenuation of neophobia (AN) as a recognition memory index, based on the supposition that to display AN rats must recognize the taste as familiar and recall that the solution is safe to drink (Gutierrez et al. 2003b).

The behavioral results obtained on taste recognition memory revealed that attenuation of neophobia was prevented by scopolamine, which indicates that the transition from novel to familiar was not accomplished or that the categorization as a safe edible was prevented, and hence the animals still showed neophobia on the second taste presentation as proposed elsewhere (Gutierrez et al. 2003a,b). It should be noted that scopolamine prevented attenuation of neophobia even when it was administered after taste stimulation, which provides support to the idea that activation of cortical muscarinic receptors is necessary to consolidate this memory. Importantly, the same treatment has no noticeable effect on consolidation of CTA, which indicates that attenuation of neophobia and conditioned taste aversion seems to rely on different cortical processes once the rat has sampled the taste and formed a representation of it (Gutierrez et al. 2003b).

The impairment of taste recognition memory induced by alteration in perirhinal cholinergic cortical activity accords with the impairment found in previous studies using microinjections of scopolamine into monkey perirhinal cortex on a visual recognition memory task (Tang et al. 1997) and those reported in rats (Warburton et al. 2003) in which scopolamine treatment administered intraperitoneally or directly into the perirhinal cortex disrupted acquisition and/or consolidation of recognition memory on a preferential exploration task. This task uses the innate preference of rats to explore novel over familiar objects. Hence, the difference in time that a rat spends in contact with a novel object minus the time it spends with the familiar object is used as a spontaneous recognition memory index; scopolaminetreated animals spend similar times with both novel and "familiar" objects, indicating that the "familiar" object did not lose its "novelty qualities." These results indicate that the ability of scopolamine to prevent the transition from novel to familiar is not limited to taste stimuli.

Recently a link was demonstrated between the cholinergic system, long lasting depression (LLD), and recognition memory (Warburton et al. 2003). First, it has been reported that in the perirhinal and surrounding cortices, some neurons decrease their activity after repetition of a novel vi- 
sual stimulus (Zhu et al. 1995). These results support the view that recognition memory could be mediated by neuronal depression, probably in the perirhinal cortex (Brown and Xiang 1998). Second, it has been proposed that cholinergic muscarinic receptor activity might be responsible for the depression presumably induced by recognition memory. In this regard, Massey et al. (2001) reported that activation of muscarinic receptors induces a long-lasting depression in perirhinal cortex slices; this synaptic depression is blocked by scopolamine but not by the NMDA receptor antagonist AP-5. Importantly, attenuation of neophobia was affected exclusively by blockade of muscarinic but not NMDA or AMPA receptors. In additional support of this idea, Warburton et al. (2003) reported that cholinergic antagonism induced by scopolamine selectively impaired LLD with no apparent effect on long-term potentiation (LTP) in perirhinal cortex slices. All in all, because there is converging evidence that muscarinic receptors participate in recognition memory, the activation of these receptors seems to induce a long-lasting depression, and their blockade affects specifically LLD and not LTP, these results indicate that cholinergic neurotransmission of perirhinal cortex is essential for recognition memory (Warburton et al. 2003). Our results are very consistent with this evidence and provide additional support of the view that cortical cholinergic muscarinic receptor activity is involved in different forms of recognition memory and in particular the recognition involved in taste information. However, it is still not clear if drinking a novel taste stimulus triggers synaptic depression in the perirhinal or insular cortex and if scopolamine could prevent these events. Further electrophysiological and biochemical studies are necessary to answer these questions.

The present results also indicate that blockade of perirhinal muscarinic but not NMDA or AMPA receptors impair the shortand long-term memory of CTA. These results provide additional support to the idea that the perirhinal cortex participates in CTA, as previously suggested (Fitzgerald and Burton 1983; Tassoni et al. 2000). Furthermore, the current data also provide neurochemical support of the idea that perirhinal cortex participation in taste aversion learning could be different from that of the insular cortex (gustatory part). Although scopolamine produces CTA impairment when injected in both cortices, NMDA and AMPA receptor blockers impaired CTA when they were microinjected into the insular cortex only (Berman et al. 2000; Ferreira et al. 2002; Gutierrez et al. 2003a). These results indicate that the perirhinal cortex participates in taste aversion learning, probably in an NMDA and AMPA receptor activity-independent manner. In addition, these results indicate that muscarinic receptor activity might be used in both perirhinal and insular cortices in the formation of the taste memory trace. Nevertheless, when scopolamine was injected immediately after taste intake but before the induction of malaise, no disruption was observed in CTA. This indicates that other memory components susceptible to be associated with malaise are in other brain structures like the insular cortex or amygdala (Gutierrez et al. 1999, 2003b). Similar results were found in the insular cortex (Naor and Dudai 1996), which also provides support of the idea that scopolamine does not interfere with the association between the taste memory trace and the malaise. These results are consistent with a previous report showing that perirhinal cortex might be relevant only in the early stages of the conditioned taste aversion learning (Tassoni et al. 2000).

In a previous study we demonstrated that scopolamine injected in the insular cortex impairs short-term memory of CTA only when rats drank saccharin after scopolamine treatment and not when scopolamine was administrated immediately after taste experience or before the short-term memory test (Ferreira et al. 2002). Although here scopolamine was administered only before taste presentation, it is reasonable to suggest that the observed short-term memory disruption was due to an indirect effect of the impairment induced on the taste memory trace rather than a direct effect on the association or consolidation of taste aversion learning.

The blockade of cholinergic muscarinic receptors of insular or perirhinal cortex seems to impair CTA in a similar manner. This indicates not only that the cholinergic mechanism is being shared by both insular and perirhinal cortex to form the taste memory trace but also that this cortical muscarinic-dependent process is not cortically redundant because perirhinal muscarinic-dependent activity could not be taken over by insular cortex receptors or vice versa. From this it can be proposed that the formation of the taste memory trace may occur in parallel and in distributed assemblies of neurons throughout the brain.

In addition, it has been demonstrated using a familiar saccharin solution that rats with ablations of the perirhinal cortex acquired spatial contextual control over liquid intake (saccharin or water). These animals show reduced liquid intake (familiar saccharin or water) in a place that has been paired with malaise (LiCl i.p. injection) compared with the consumption displayed in a place paired with saline injection (Howse et al. 2003), disclosing that rats lacking perirhinal cortex can acquire taste aversion learning to familiar taste stimuli. Although the Howse report seems to conflict with the present results and to those published by Tassoni et al. (2000), this is not necessarily the case. Importantly, compensatory redundant pathways could emerge after a chronic lesion (Gutierrez et al. 1999a). Also, the effect of this lesion has not been analyzed using a novel taste stimulus instead of a familiar one. Different anatomical and neurochemical substrates might be recruited by CTA learning depending on whether or not the rat had previous experience with the taste stimulus (Berman and Dudai 2001). For example, rats with ablations of the insular cortex displayed a deficiency in CTA only when they were trained with a novel taste (Kiefer and Braun 1977).

In summary, the present results indicate that perirhinal cortex participates in CTA, mainly during the formation of the taste memory trace. Furthermore, our results support a role of perirhinal cholinergic muscarinic receptors on taste recognition memory, extending previous results that support the participation of these receptors on recognition memory (Warburton et al. 2003) and also demonstrating that perirhinal cortex is concerned in the transition from novel to familiar safe taste.

\section{MATERIALS AND METHODS}

\section{Subjects}

Male Wistar rats (260-300 g) were used. They were housed in individual cages, with $12 \mathrm{~h}$ light/dark cycle and maintained at $22^{\circ} \mathrm{C}$. All behavioral manipulations were performed inside the vivarium during the light phase. Rats received ad libitum lab chow throughout the experiment. Experiments were performed in accordance with Rules in Health Matters (Ministry of Health, Mexico) and with approval of the local Animal Care Committee.

\section{Reagents}

The muscarinic receptor antagonist scopolamine hydrobromide (Scop; SIGMA), the NMDA receptor antagonist, D,L-2-amino-5phosphonovaleric acid (AP-5; RBI), and the AMPA receptor antagonist, 2,3-dioxo-6-nitro-1,2,3,4-tetrahydrobenzo[f] quinoxaline-7-sulfonamide disodium (NBQX; Tocris Cookson) were dissolved in Ringer solution $(118 \mathrm{mM} \mathrm{NaCl}, 4.7 \mathrm{mM} \mathrm{KCl}, 1.2 \mathrm{mM}$ $\mathrm{KH}_{2} \mathrm{PO}_{4}, 1.2 \mathrm{mM} \mathrm{MgSO}, 2.5 \mathrm{mM} \mathrm{CaCl}_{2}, 19 \mathrm{mM} \mathrm{NaHCO}_{3}$, and $3.3 \mathrm{mM} \mathrm{C}_{6} \mathrm{H}_{12} \mathrm{O}_{6}$; J.T. Baker), which, in turn, was used as vehicle. The concentrations used were $60 \mu \mathrm{g} / \mu \mathrm{L}$ scopolamine, $10 \mu \mathrm{g} / \mu \mathrm{L}$ $\mathrm{AP}-5$, and $5 \mu \mathrm{g} / \mu \mathrm{L} \mathrm{NBQX}$, according to previous reports showing 
CTA learning impairment when these specific concentrations were applied to the gustatory cortex (Insular Cortex; Gutierrez et al. 1999b, 2003a; Berman et al. 2000; Ferreira et al. 2002). All other chemicals were of analytical grade or the highest grade available.

\section{Surgery and Microinjection}

Animals were anesthetized with sodium pentobarbital $(65 \mathrm{mg} /$ $\mathrm{kg}$ ) and mounted in the stereotaxic apparatus. A midline incision was made, and the lateral muscle was slightly detached, exposing the lateral border of the skull. Two holes were made at the following coordinates: anterior-posterior, $-3 \mathrm{~mm}$; lateral, \pm 6.5 $\mathrm{mm}$ relative to Bregma (Paxinos and Watson 1998). The tips of two stainless steel guide cannulae aimed at the perirhinal cortex were inserted bilaterally $5 \mathrm{~mm}$ below Bregma. Two screws were implanted and served as anchors in the skull bone. The whole assembly was attached to the skull with acrylic dental cement. A stylus was inserted into the guide cannula to prevent clogging. Rats were allowed to recover from surgery for at least $5 \mathrm{~d}$ before the beginning of behavioral training.

Microinjections were given bilaterally via a 30-gauge stainless steel injector $2.2 \mathrm{~mm}$ larger than the tips of the guide cannulae, connected via Teflon tubing to a $10-\mu \mathrm{L}$ glass microsyringe attached to a microinfusion pump (Carnegie Medicin). Infusions of $0.5 \mu \mathrm{L}$ were given per hemisphere over $1 \mathrm{~min}$. The injector was left in the guide cannula one additional minute to allow complete diffusion. Intracortical infusions were given to handrestrained conscious animals.

\section{Behavioral Procedures and Experimental Design}

\section{Neophobia and Attenuation of Neophobia (AN)}

We used the same protocol as in our previous study (Gutierrez et al. 2003a) with a highly concentrated saccharin solution, which enhances the robustness of neophobia (Domjan 1976). Briefly, as with CTA, rats were water-deprived for $24 \mathrm{~h}$, and then they were given daily access to tapwater for $15 \mathrm{~min}$ during $3 \mathrm{~d}$ in their home cages. Volume consumption was registered with $0.5-\mathrm{mL}$ accuracy. On day 4 , animals were counterbalanced by weight and sorted into their corresponding groups, as described below, and the neophobic response was tested by presentation of $0.5 \%(\mathrm{w} / \mathrm{v})$ sodium saccharin solution (SIGMA) for $15 \mathrm{~min}$. To ensure that all animals consumed their daily fluid requirements regardless of their consumption of saccharin, an additional 15 min of water access was given. The same saccharin procedure was repeated on two consecutive days as an attenuation of neophobia test (AN). Thus, the neophobic response was analyzed in terms of the reduction in the intake of a novel taste solution relative to water baseline intake, and AN was indicated by the increased consumption of saccharin in the following presentations.

Four groups (Veh, $n=16$; Scop, $n=19$; AP5, $n=8$ or NBQX, $n=8$ ) received a single bilateral microinjection in the perirhinal cortex $20 \mathrm{~min}$ prior to the novel $0.5 \%$ saccharin solution on day 4 (Fig. 1A). Two additional groups (Veh-A, $n=18$; Scop-A, $n=19$ ) were microinjected immediately after taste presentation on day 4 (Fig. 1B). Two independent experiments were performed for the groups that received either scopolamine or vehicle. The results were very similar so the groups were pooled together. The results of these two subgroups were very similar, and because the differences were insignificant, they were pooled together.

\section{Conditioned Taste Aversion (CTA): Long-Term Memory Test}

Rats were water-deprived for $24 \mathrm{~h}$ and then were given $15 \mathrm{~min}$ of tapwater access in their home cage every day for four consecutive days. On the following day, the acquisition trial was performed by presentation of $0.1 \%(\mathrm{w} / \mathrm{v})$ saccharin (in distilled water) for 15 min; 15 min later, after saccharin exposure was accomplished, a malaise-inducing drug (lithium chloride, $0.4 \mathrm{M} \mathrm{LiCl} ; 2.94 \mathrm{mEq} /$ $\mathrm{kg}$; Baker) was injected intraperitoneally. Two subsequent drinking sessions were performed with water only, and $72 \mathrm{~h}$ after the acquisition trial, the long-term memory test trial was conducted. The test trial consisted in the presentation of $0.1 \%$ saccharin solution for a second time, and the decrease in consumption compared with water baseline was used as a measure of the strength of aversion.

Four groups received a single bilateral microinjection of vehicle (Veh, $n=10$ ), scopolamine (Scop, $n=9$ ), a NMDA receptor antagonist (AP5, $n=13$ ), or an AMPA receptor antagonist (NBQX, $n=8$ ) in the perirhinal cortex 20 min prior to the novel taste presentation on the acquisition trial (Fig. 2A). Two additional groups received a microinfusion of either vehicle (Veh-A, $n=7$ ) or scopolamine (Scop-A, $n=8$ ) immediately after taste presentation on the acquisition trial (Fig. 2B).

\section{Conditioned Taste Aversion: Short-Term Memory Test}

We used the same protocol as in our previous study (Ferreira et al. 2002). Briefly, from day 1 to day 4, two groups of rats were trained to drink water twice a day in their home cages. Each morning subjects had access to $10 \mathrm{~mL}$ of tapwater during a 15min period; then, $4.5 \mathrm{~h}$ later, they had ad libitum access to water for another $15 \mathrm{~min}$, and the average of this second consumption was taken as a baseline measure (Fig. 3). On day 5, 20 min before the beginning of the acquisition trial, one group received a single microinjection of vehicle (Veh, $n=9$ ), whereas the other received scopolamine (Scop, $n=10$ ). In the acquisition trial, rats were allowed to drink $10 \mathrm{~mL}$ of novel $0.1 \%(\mathrm{w} / \mathrm{v})$ saccharin in distilled water, and 15 min later, a malaise-inducing drug $(0.4 \mathrm{M} \mathrm{LiCl}$; $2.94 \mathrm{mEq} / \mathrm{kg}$ ) was injected intraperitoneally. Then, $4.5 \mathrm{~h}$ after first taste presentation, rats had ad libitum access to saccharin solution for $15 \mathrm{~min}$ as the short-term memory test. After saccharin exposure, $15 \mathrm{~min}$ of water access was given to avoid dehydration and to discard unspecific general fluid intake reduction. A 4.5-h interval was used to measure short-term memory to allow recovery from the poison-like effects induced by $\mathrm{LiCl}$ administration. Previous reports showed that lying on the belly (LOB), a behavioral index of malaise, dissipates within $2 \mathrm{~h}$ (Lamprecht et al. 1997), and our previous observation indicates that after $4.5 \mathrm{~h}$, rats ingest $60 \%$ of the liquid during a 15 -min session, compared with water baseline intake (Ferreira et al. 2002).

During the next two days, baseline water intake was reestablished. Rats were exposed to saccharin solution $72 \mathrm{~h}$ after the acquisition trial for the third time to assess long-term memory of CTA.

\section{Histology}

At the end of the experiments, all rats were killed by an overdose of pentobarbital and perfused with saline followed by $0.4 \%$ paraformaldehyde. The brains were removed and placed in $30 \%$ sucrose/PB $0.1 \mathrm{M}$ solution. Brains were sectioned and stained with Cresyl Violet to establish the place of microinjection.

\section{Statistical Analysis}

A one- or two-way ANOVA was used to compare means ( \pm SEM) of milliliters of consumed water or saccharin among groups, presented as a percentage of the water consumed during baseline. The Fisher pairwise test was used for post hoc analysis with $p<0.05$ considered significant.

\section{ACKNOWLEDGMENTS}

This work was supported by CONACYT-Mexico grants MRI 35806-N and DGAPA-IN215001. We acknowledge the technical assistance of Federico Jandete, Oreste Carbajal, Francisco Pérez Eugenio, and Yolanda Díaz de Castro and give thanks to Enrique Espinosa and Paul Afolabi Remi for English revision of the final text.

The publication costs of this article were defrayed in part by payment of page charges. This article must therefore be hereby marked "advertisement" in accordance with 18 USC section 1734 solely to indicate this fact.

\section{REFERENCES}

Aigner, T. and Mishkin, M. 1986. The effects of physostigmine and scopolamine on recognition memory in monkeys. Behav. Neural Biol. 45: $81-87$. 
Bartoshuk, L.M. 1979. Bitter taste of saccharin related to the genetic ability to taste the bitter substance 6- $n$-propylthiouracil. Science 205: 934-935.

Berman, D.E. and Dudai, Y. 2001. Memory extinction, learning anew, and learning the new: Dissociations in the molecular machinery of learning in cortex. Science 291: 2417-2419.

Berman, D.E., Hazvi, S., Neduva, V., and Dudai, Y. 2000. The role of identified neurotransmitter systems in the response of insular cortex to unfamiliar taste: Activation of ERK1-2 and formation of a memory trace. J. Neurosci. 20: 7017-7023.

Bermudez-Rattoni, F. and Yamamoto, T. 1998. Neuroanatomy of CTA: Lesion studies. In Conditioned taste aversion. Memory of a special kind (eds. J. Bures et al.), pp. 28-44. Oxford University Press, New York.

Best, M.R., Domjan, M., and Haskins, W.L. 1978. Long-term retention of flavor familiarization: Effects of number and amount of prior exposures. Behav. Biol. 23: 95-99.

Brown, M.W. and Xiang, J.-Z. 1998. Recognition memory: Neural substrates of the judgment of prior occurrence. Prog. Neurobiol. 55: $149-189$.

Buffalo, E.A., Ramus, S.J., Clark, R.E., Teng, E., Squire, L.R., and Zola, S.M. 1999. Dissociation between the effects of damage to perirhinal cortex and area TE. Learn. Mem. 6: 572-599.

Buresova, O. and Bures, J. 1980. Post-ingestion interference with brain function prevents attenuation of neophobia in rats. Behav. Brain Res. 1: $299-312$.

Burwell, R.D. 2001. Borders and cytoarchitecture of the perirhinal and postrhinal cortices in the rat. J. Comp. Neurol. 437: 17-41.

Burwell, R.D. and Amaral, D.G. 1995. Cortical afferents to the perirhinal, post-rhinal and entorhinal cortices of the rat. Hippocampus 5: 390-408.

1998. Perirhinal and postrhinal cortices of the rat: Interconnectivity and connections with the enthorinal cortex. J. Comp. Neurol. 391: 293-321.

Deacon, T.W., Eichenbaum, H., Rosenberg, P., and Eckmann, K.W. 1983. Afferent connections of the perirhinal cortex in the rat. $J$. Comp. Neurol. 220: 168-190.

Domjan, M. 1976. Determinants of the enhancement of flavored-water intake by prior exposure. J. Exp. Psychol., Anim. Behav. Proces. 2: 17-27.

Ellis, M.E. and Kesner, R.P. 1981. Physostigmine and norepinephrine: Effects of injection into the amygdala on taste associations. Physiol. Behav. 27: 203-209.

Ferreira, G., Gutierrez, R., De, L., and Bermudez, R. 2002. Differential involvement of cortical muscarinic and NMDA receptors in shortand long-term taste aversion memory. Eur. J. Neurosci. 16: $1139-1145$.

Fitzgerald, R.E. and Burton, M.J. 1983. Neophobia and conditioned taste aversion deficits in the rat produced by undercutting temporal cortex. Physiol. Behav. 30: 203-206.

Goulet, S. and Murray, E.A. 2001. Neural substrates of crossmodal association memory in monkeys: The amygdala versus the anterior rhinal cortex. Behav. Neurosci. 115: 271-284.

Gutierrez, H., Gutierrez, R., Ramirez, T., Silva, G., Ormsby, C.E. Miranda, M.I., and Bermudez, R. 1999a. Redundant basal forebrain modulation in taste aversion memory formation. J. Neurosci. 19: 7661-7669.

Gutierrez, H., Hernandez-Echeagaray, E., Ramirez-Amaya, V., and Bermudez-Rattoni, F. 1999b. Blockade of $N$-methyl-D-aspartate receptors in the insular cortex disrupts taste aversion and spatial memory formation. Neuroscience 89: 751-758.

Gutierrez, R., Tellez, L.A., and Bermudez-Rattoni, F. 2003a. Blockade of cortical muscarinic but not NMDA receptors prevents a novel taste from becoming familiar. Eur. J. Neurosci. 17: 1556-1562.

Gutierrez, R., Rodriguez-Ortiz, C.J., De La Cruz, V., Núñez-Jaramillo, L., and Bermudez-Rattoni, F. 2003b. Cholinergic dependence of taste memory formation: Evidence of two distinct processes. Neurobiol. Learn. Mem. 80: 323-331.

Howse, D.J., Squires, A.S., Martin, G.M., and Skinner, D.M. 2003. Perirhinal cortex lesions impair context aversion learning. Learn. Mem. 10: 161-167.

Kiefer, S.W. and Braun, J.J. 1977. Absence of differential associative responses to novel and familiar taste stimuli in rats lacking gustatory neocortex. J. Comp. Physiol. Psychol. 91: 498-507.

Kowalska, D.M., Kusmierek, P., Kosmal, A., and Mishkin, M. 2001. Neither perirhinal/entorhinal nor hippocampal lesions impair short-term auditory recognition memory in dogs. Neuroscience 104: $965-978$.
Lamprecht, R. and Dudai, Y. 1996. Transient expression of c-Fos in rat amygdala during training is required for encoding conditioned taste aversion memory. Learn. Mem. 3: 31-41.

Lamprecht, R., Hazvi, S., and Dudai, Y. 1997. cAMP response element-binding protein in the amygdala is required for long- but not short-term conditioned taste aversion memory. J. Neurosci. 17: $8443-8450$

Malkova, L., Bachevalier, J., Mishkin, M., and Saunders, R.C. 2001. Neurotoxic lesions of perirhinal cortex impair visual recognition memory in rhesus monkeys. Neuroreport 12: 1913-1917.

Mandler, G. 1980. Recognizing: The judgment of previous occurrence. Psychol. Rev. 87: 252-271.

Martin, S.J. and Morris, R.G.M. 2002. New life in an old idea: The synaptic plasticity and memory hypothesis revisited. Hippocampus 12: 609-636.

Massey, P.V., Bhabra, G., Cho, K., Brown, M.W., and Bashir, Z.I. 2001. Activation of muscarinic receptors induces protein synthesis-dependent long-lasting depression in the perirhinal cortex. Eur. J. Neurosci. 14: 145-152.

McDonald, A.J. and Jackson, T.R. 1987. Amygdaloid connections with posterior insular and temporal cortical areas in the rat. J. Comp. Neurol. 262: 59-77.

Meunier, M., Bachevalier, J., Mishkin, M., and Murray, E.A. 1993. Effects on visual recognition of combined and separate ablations of the entorhinal and perirhinal cortex in rhesus monkeys. J. Neurosci. 13: $5418-5432$.

Mumby, D.G. and Pinel, J.P.J. 1994. Rhinal cortex lesions and object recognition in rats. Behav. Neurosci. 108: 11-18.

Murray, E.A. and Richmond, B.J. 2001. Role of perirhinal cortex in object perception, memory and associations. Curr. Opin. Neurobiol. 11: $188-193$.

Myers, R. 1966. Injection of solutions into cerebral tissue: Relation between volume and diffusion. Physiol. Behav. 1: 171-174.

Nachman, M. and Jones, D.R. 1974. Learned taste aversions over long delays in rats: The role of learned safety. J. Comp. Physiol. Psychol. 86: 949-956.

Naor, C. and Dudai, Y. 1996. Transient impairment of cholinergic function in the rat insular cortex disrupts the encoding of taste in conditioned taste aversion. Behav. Brain Res. 79: 61-67.

Otto, T. and Eichenbaum, H. 1992. Complementary roles of the orbital prefrontal cortex and the perirhinal-entorhinal cortices in an odor-guided delayed-nonmatching-to-sample task. Behav. Neurosci. 106: $762-775$.

Parker, A. and Gaffan, D. 1998. Lesions of the primate rhinal cortex cause deficits in flavour-visual associative memory. Behav. Brain Res. 93: 99-105.

Paxinos, G. and Watson, C. 1998. The rat brain in stereotaxic coordinates. 4 th edition, Academic Press, New York.

Sipos, M.L., Burchnell, V., and Galbicka, G. 1999. Dose-response curves and time-course effects of selected anticholinergics on locomotor activity in rats. Psychopharmacology (Berl) 147: 250-256.

Smith, J.C. 2000. Microstructure of the rat's intake of food, sucrose and saccharin in 24-hour test. Neurosci. Biobehav. Rev. 24: 199-212.

Tang, Y., Mishkin, M., and Aigner, T.G. 1997. Effects of muscarinic blockade in perirhinal cortex during visual recognition. Proc. Natl. Acad. Sci. 94: 12667-12669.

Tassoni, G., Lorenzini, C.A., Baldi, E., Sacchetti, B., and Bucherelli, C. 2000. Role of the perirhinal cortex in rats' conditioned taste aversion response memorization. Behav. Neurosci. 114: 875-881.

Warburton, E.C., Koder, T., Cho, K., Massey, P.V., Duguid, G., Bashir, Z.I., and Brown, M.W. 2003. Cholinergic neurotransmission is essential for perirhinal cortical plasticity and recognition memory. Neuron 38: 987-996.

Yasoshima, Y. and Yamamoto, T. 1997. Rat gustatory memory requires protein kinase $\mathrm{C}$ activity in the amygdala and cortical gustatory area. Neuroreport 8: 1363-1367.

Yasoshima, Y., Morimoto, T., and Yamamoto, T. 2000. Different disruptive effects on the acquisition and expression of conditioned taste aversion by blockades of amygdalar ionotropic and metabotropic glutamatergic receptor subtypes in rats. Brain Res. 869: $15-24$.

Zhu, X.O., Brown, M.W., and Aggleton, J.P. 1995. Neuronal signalling of information important to visual recognition memory in rat rhinal and neighbouring cortices. Eur. J. Neurosci. 7: 753-765.

Received August 28, 2003; accepted in revised form November 21, 2003 


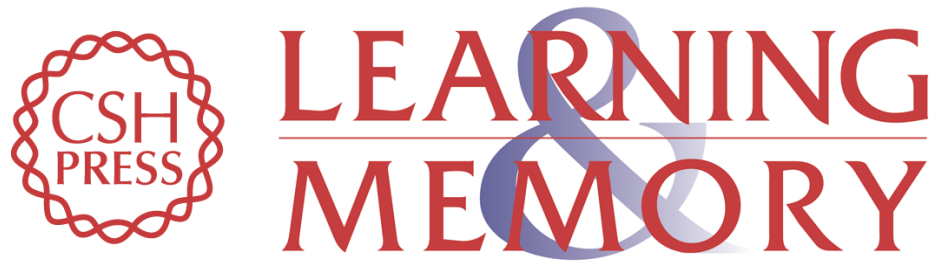

\section{Perirhinal Cortex Muscarinic Receptor Blockade Impairs Taste Recognition Memory Formation}

Ranier Gutiérrez, Vanesa De la Cruz, Carlos J. Rodriguez-Ortiz, et al.

Learn. Mem. 2004, 11:

Access the most recent version at doi:10.1101//m.69704

References This article cites 45 articles, 10 of which can be accessed free at:

http://learnmem.cshlp.org/content/11/1/95.full.htmI\#ref-list-1

License

Email Alerting Receive free email alerts when new articles cite this article - sign up in the box at the Service top right corner of the article or click here. 